\title{
A Study of Degradation in Vegetable Oils by Exposure to Sunlight Using Fourier Transform Infrared Spectroscopy
}

\author{
Thiago Reixach Pires de Souza1, Laudilene Olenka², Wilson Sacchi Peternella1* \\ ${ }^{1}$ Department of Chemistry, Federal University of Rondônia, Campus José Ribeiro Filho, Porto Velho, State of Rondônia, Brazil \\ ${ }^{2}$ Department of Physics, Federal University of Rondônia, Campus José Ribeiro Filho, Porto Velho, State of Rondônia, Brazil \\ Email: *wpeternella@yahoo.com
}

How to cite this paper: de Souza, T.R.P., Olenka, L. and Peternella, W.S. (2020) A Study of Degradation in Vegetable Oils by Exposure to Sunlight Using Fourier Transform Infrared Spectroscopy. Materials Sciences and Applications, 11, 678-691. https://doi.org/10.4236/msa.2020.1110046

Received: September 10, 2020

Accepted: October 19, 2020

Published: October 22, 2020

Copyright $\odot 2020$ by author(s) and Scientific Research Publishing Inc. This work is licensed under the Creative Commons Attribution International License (CC BY 4.0).

http://creativecommons.org/licenses/by/4.0/

\begin{abstract}
There are a diversity and variability of oil producing plants and different extraction methods. These vegetable and essential oils are substances stored and released by plants from their fruits, leaves, flowers, bark and stem, being complete of plant origin that provides some benefits. In the plant these oils are also known as antioxidant substances, which have the function of natural protection. It is known that the extraction method has a strong influence on its quality and composition due to its variability and environmental conditions, besides possible adulteration. Oils that are rich in polyunsaturated fatty acids are the most relevant to the cosmetic industry but are most sensitive to oxidation. The oxidation of these oils generates what is known as rancidity, with the presence of smaller and undesirable molecules, thus reducing the quality of the oil beyond its nutritional value, making them harmful to human health. Stocking conditions, such as exposure to sunlight and heat, are major phenomena that accelerate the degradation of these oils. Infrared spectrometry with Fourier transform (FTIR) is a tool with potential to evaluate the degradation effect of vegetable oils. Infrared spectra of Almond (Prunus dulcis), Andiroba (Carapa guianensis aubl.), Copaíba (Copaifera langsdorffi) and Rosehip (Rosa aff. Rubiginosa) oils before and after exposure to sun light for 90 days were analyzed, with objective of evaluating the effect of the degradation on the composition of the oil, which were acquired in local commerce of the city Porto Velho. The spectra trends show the occurrence of oxidation, with the reduction of unsaturation, in addition to the fractionation of carbon chains and appearance of functional groups such as aldehyde and alcohol.
\end{abstract}

\section{Keywords}

Vegetable Oil, Oxidation, Unsaturation, FTIR 


\section{Introduction}

Vegetable oils are natural substances and insoluble in water, obtained from oleaginous species, and according to Farias et al. [1], consist of triacylglycerides, which are esters formed between glycerol and three fatty acids. However, in addition to having fatty acids and glycerides in their composition, vegetable oils are also made up of some substances such as steroids, tocopherols, phenols, flavonoids, volatile compounds, vitamins, pigments, etc., as described by Herman and Esteves, apud Pereira [2].

Vegetable oils, some also called essential oils, are substances that help plants to grow, a defense system in the protection against parasites and pollination, according to Silva [3], whose difference is in the form and procedure of how this essential oil will be extracted, part of the plant will be used in the extraction process, such as fruits, flowers, leaves, bark and stems, being widely consumed by the population for producing some benefit, applied to human health as a cosmetic product and also in food.

Among the fatty acids that form the tri-esters of lipids in vegetable oils, unsaturated fatty acids stand out, as they have important functions in the human body. According to Allinger et al. [4] the most important unsaturated fatty acids obtained by fat hydrolysis are oleic, linoleic and linolenic acids.

As described by Rampazzo [5], oils and fats are of relevant importance in the body, as caloric sources, of essential fatty acids, in addition to transporters of fat-soluble vitamins, nutrients and antioxidants. Also according to Rampazzo [5], unlike saturated and monounsaturated fatty acids that can be synthesized by the body and easily obtained in the diet, some polyunsaturated fatty acids, known as essential fatty acids, having as examples, the important omegas ( $\omega-3$ and $\omega-6$ ), cannot be synthesized by the body, and must be obtained through the consumption of foods rich in the respective acids, observing that there are few sources rich in essential fatty acids, the most common being in the diet, the fish.

However, several authors have demonstrated the existence of vegetable oils rich in polyunsaturated fatty acids, such as Andiroba (Carapa guianensis), Copaiba (Copaifera langsdorffii), Almonds (Prunus dulcis) and Rosehip (Rosa aff. rubiginosa), as shown in Table 1.

As described by Pereira [2], $\alpha$-linolenic and linoleic fatty acids belong to the ( $\omega-3$ and $\omega-6)$ families, respectively, that is, they are essential fatty acids.

Also according to Pereira [2], the intake of essential fatty acids, such as ( $\omega-3$ and $\omega-6$ ), are very important, as it is known that they help to reduce blood cholesterol levels and perform valuable physiological functions to living organisms. Since they are present in the formation, development and functioning of the brain and retina, they are still abundant in most cells of these organs.

According to Silva [6] and Ferrari et al. [10], Andiroba, C. guianensis is a tree of the Meliaceae family, occurring in central America up to the north of South America (Venezuela, Ecuador, Colombia, Peru and Brazil). It stands out as large, reaching up to about 30 meters in height. Andiroba oil has a long medicinal 
Table 1. Fatty acid content in vegetable oils from Carapa guianensis, Copaifera langsdorffii, Prunus dulcis, and Rosa aff. rubiginosa.

\begin{tabular}{ccccc}
\hline Substance & $\begin{array}{c}\text { C. guianensis } \\
\text { (A) }\end{array}$ & $\begin{array}{c}\text { C. langsdorffii } \\
\text { (B) }\end{array}$ & $\begin{array}{c}\text { P. dulcis } \\
\text { (C) }\end{array}$ & $\begin{array}{c}\text { R.rubiginosa } \\
\text { (D) }\end{array}$ \\
\hline Arachidonic acid & $2.26 \%$ & $1.10 \%$ & $0.10 \%-0.50 \%$ & $0-1.00 \%$ \\
Behenic acid & $0.55 \%$ & $3.00 \%$ & - & $0-1.00 \%$ \\
Stearic acid & $10.53 \%$ & - & $1.00 \%-10.00 \%$ & $1.00 \%-2.00 \%$ \\
Linoleic acid & $12.93 \%$ & $35.70 \%$ & $20.00 \%-34.00 \%$ & $43.00 \%-49.00 \%$ \\
Linolenic acid & - & - & - & $32.00 \%-38.00 \%$ \\
Oleic acid & $42.71 \%$ & $35.30 \%$ & $43.00 \%-70.00 \%$ & $14.00 \%-16.00 \%$ \\
Palmitic acid & $31.02 \%$ & $24.90 \%$ & $4.00 \%-13.00 \%$ & $3.00 \%-5.00 \%$ \\
\hline
\end{tabular}

Letters in parentheses correspond to source: (A) Silva [6], (B) Silva [7], (C) Askin et al. [8] and (D) Valladares apud Santos et al. [9].

history and as a herbal medicine, is used mainly in South America. It is estimated that in Brazil, the annual consumption of andiroba oil is 30 thousand liters, while the export is on average 450 thousand liters per year.

According to Silva [7], Copaíba, C. langsdorffii, popularly known as copaíba, is found in the Amazon. From this plant, an oil-resin can be extracted from its stem, which is used in folk medicine as a bactericide and anti-inflammatory.

According to Ferreira [11], the Almond tree, $P$. dulcis is a commercially cultivated species, having its origin in Central Asia. Almond trees can be grown in temperate, warm and subtropical climates. The adaptation in certain regions, allows the plants to survive in semi-arid climates, with low precipitation $(<150$ $\mathrm{mm})$.

The Rosehip, Rosa aff. rubiginosa as described by Santos et al. [9], originally from the Mediterranean area and Central Europe, was brought to South America by Spanish colonists, and grows in southern and central Chile as a wild plant of low agricultural value. It is known that its oil is popularly used as a herbal medicine to treat skin diseases and largely by the cosmetics industry.

However, according to Rampazzo [5], although vegetable oils used in food are less harmful to health, we have to take into account some important issues. Comparing them to animal fats, which are mostly saturated, they are not easily oxidized by oxygen and other oxidizing agents, while vegetable oils due to the greater number of unsaturation are highly reactive and vulnerable to oxidation as described by Naz et al. apud Rampazzo [5]. This is one of the biggest technological obstacles to use, being able to preserve them during processing and storage, due to their sensitivity to heat and oxidation.

Based on the wide variety of oilseed species and rich in unsaturated fatty acids present in the Amazon, however, a study is needed to assess the effect of the degradation of these oils on their composition.

The Spectrophotometry in the infrared region with Fourier transform (FTIR) has been used by several authors in evaluating vegetable oils, and according to 
Souza [12] it is an excellent tool to evaluate the oxidative process in oils rich in unsaturated fatty acids. Allied to this, according to Pereira [2], FTIR shows itself as a fast and ecologically correct analytical method, as there is no need to use toxic or aggressive reagents, or even the generation of harmful residues to the environment, which causes that the use of this tool is widely applied. And according to Schneider [13], FTIR-ATR is cited by the American Oil Chemists Society, as an official method for the determination of trans isomers in vegetable oils.

It is observed in the literature that the FTIR-ATR technique has been widely used in the classification of vegetable oils, as described by Nenadis et al. [14]. According to Ismail et al. [15], however, this technique has been applied in quantitative analysis due to the fact that infrared energy is directly proportional to the concentration of substances that are present in the sample. This evaluation technique, because it is not destructive, fast and generates little chemical residue, has been widely applied in the quality control of vegetable oils as described by Uncu et al. [16], in the evaluation of the peroxide index according to Marina et al. [17], in determining the acidity index according to Jiang et al. [18].

In general, vegetable oils in the presence of oxygen, heat, light and humidity are very unstable and undergoes various types of chemical reactions of degradation, which makes their conservation difficult, taking the production and storage processes fundamental steps for the maintaining its quality as described by Simões et al. [19].

Considering as based the changes caused by the degree of establishment and consequently the difference in absorption bands, that is, their respective areas, aiming to show that the storage conditions can maintain the quality of the product intended for the population. And considering the commercial importance of vegetable oils from andiroba, copaiba, almond and rosehip, this study had as objective evaluate the effect of exposure to sunlight on these oils rich in unsaturated fatty acids by the (FTIR) technique.

\section{Methodology}

In the present work, four vegetable oils from species of our biodiversity were studied, two of them native to the Amazonian territory, Andiroba (Carapa guianensis) and Copaíba (Copaifera langsdorffii), and the other two native to the Middle East, and introduced in several regions of the land, the Almond (Prunus dulcis) and the Rosehip (Rosa aff. rubiginosa), being acquired in the local pharmaceutical trade in the city of Porto Velho.

For the assessment of degradation in the light, the $15 \mathrm{ml}$ transparent glass bottles containing the respective vegetable oils were kept for 90 days at room temperature in the city of Porto Velho State of Rondônia, with a minimum temperature during the night of approximately $23^{\circ} \mathrm{C}$ and during the day maximum temperature of approximately $35^{\circ} \mathrm{C}$, and average relative humidity of $84 \%$.

The samples, initially considered "in natura", were analyzed using the Fourier transform infrared spectrometry (FTIR) technique, and after exposure to sun- 
light radiation for 90 days, where further FTIR analyzes of the same samples were carried out under conditions similar analyzes.

For the acquisition of FTIR spectra, the Shimadzu Prestige 21 spectrometer was used, equipped with an ATR (attenuated total reflectance) accessory. FTIR spectra were recorded for a total of 20 number scans over $4000-500 \mathrm{~cm}^{-1}$ with a resolution of 4 scans on a spectrum FTIR system.

From the results obtained, comparative analyzes were carried out between the spectra before and after the exposure of the samples to sunlight, with the purpose of evaluating the degradation of the samples, based on the variation of the transmittance bands and their respective areas, with the help of the OriginPro 9.1 software.

Thus, in order to facilitate comparative analyzes between the spectra before and after exposure to sunlight, the bands in the infrared region, present in each sample, were tabulated from their wave number in which they present the greatest transmittance intensity, their area in $\mathrm{cm}^{2}$, the organic group to which it corresponds and its mode of vibration.

\section{Results and Discussion}

The evaluations carried out take into account the relationship between the area of the characteristic band of a species and its concentration, considering the relationship between the intensity of absorption in relation to the baseline of the spectrum, which in turn is directly related to the concentration of the spectrum species, represented by the area of the band in question.

Organic compounds when exposed to energy, from heat or solar radiation, can generate radicals due to the homolytic breakdown of chemical bonds. These radicals can react with other molecules, producing new radicals, and in the presence of atmospheric oxygen, generating peroxides and hydroperoxides, that is, unstable compounds that can be broken down into other even more reactive radicals as described by Solomons [20].

The self-oxidation process of these vegetable oils can be started with the removal of an allylic hydrogen from the compound, that is, a fatty acid, under conditions favored by light and temperature, generating an allyl radical. Then, these radicals can easily react with atmospheric oxygen and form peroxide radicals, which are then converted into hydroperoxides, which will act as propagators of the reaction, resulting in the formation of more stable products according to Ramalho [21].

The FTIR spectra for vegetable oils under oxidative conditions of exposure to sunlight, over of 90 days are shown in Figures 1-4, and their respective Tables 2-5, with information extracted from the FTIR spectra.

The FTIR spectra of the samples are similar, with specific differences as to the intensity of some bands, due to the fact of high amounts common to the studied oils of oleic and linoleic acids, for example. The region from 1800 to $1000 \mathrm{~cm}^{-1}$ is known as the region of digital printing, for presenting significant changes in the 


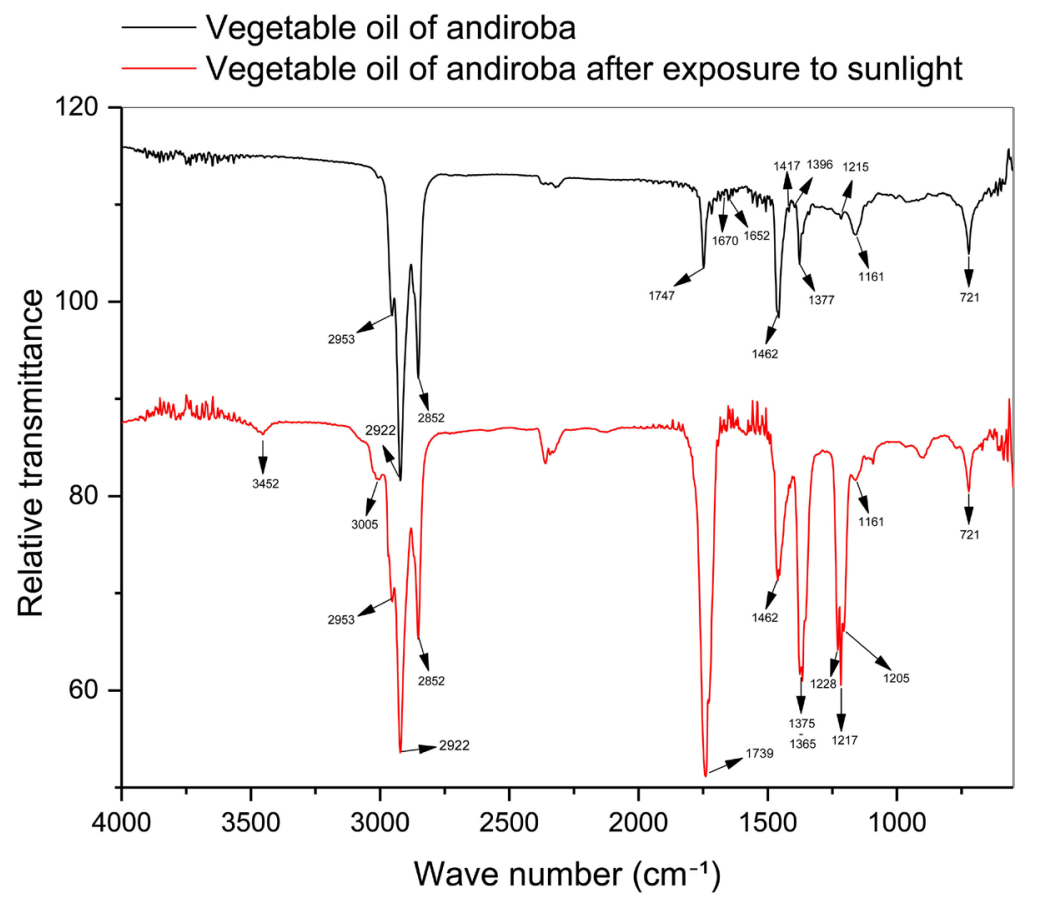

Figure 1. FTIR spectrum of Andiroba oil, before (up) and after exposure to light (down).

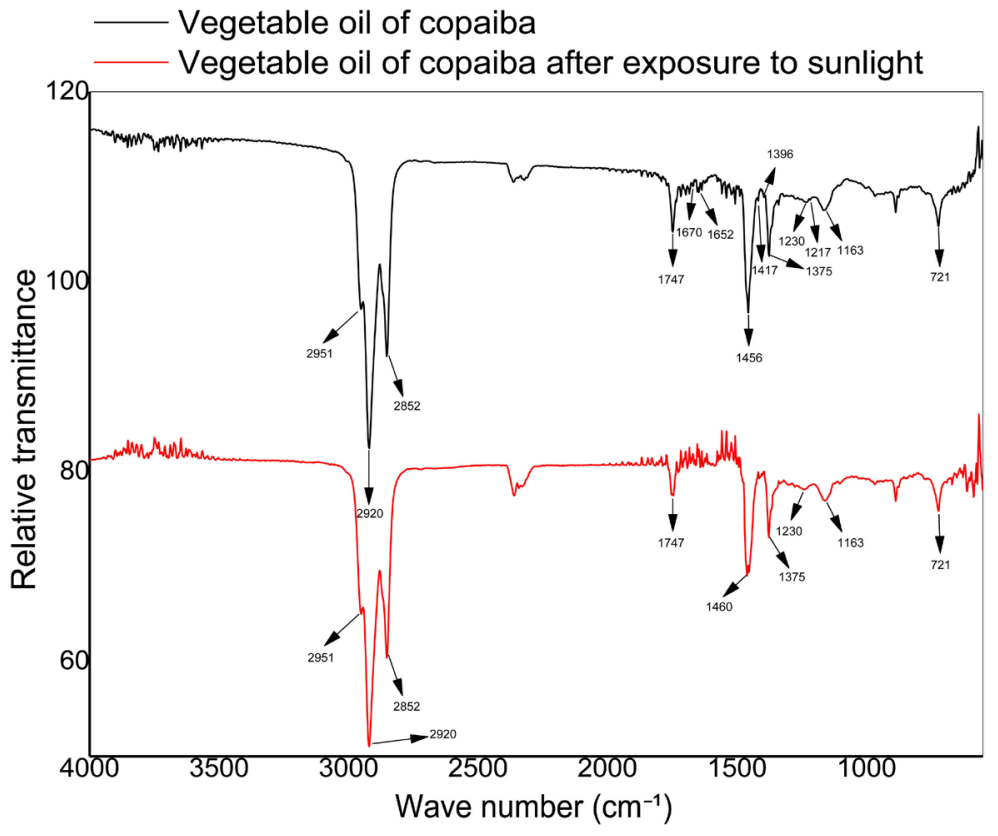

Figure 2. FTIR spectrum of Copaíba oil, before (up) and after exposure to light (down).

distribution of the absorption maximums. Thus, it is more appropriate to identify spectral changes as described by (Souza et al. [22]. In this region, the bands next of 1228 and $1161 \mathrm{~cm}^{-1}$ are observed, where they are related to saturated acyl groups according to Guill'en, et al. [23]. The infrared spectra of the oxidized samples did not reveal peaks close to $3300 \mathrm{~cm}^{-1}$ indicating the absence of hydroperoxides, which are normally formed during oxidation as described by Srivastava et al. [24]. 


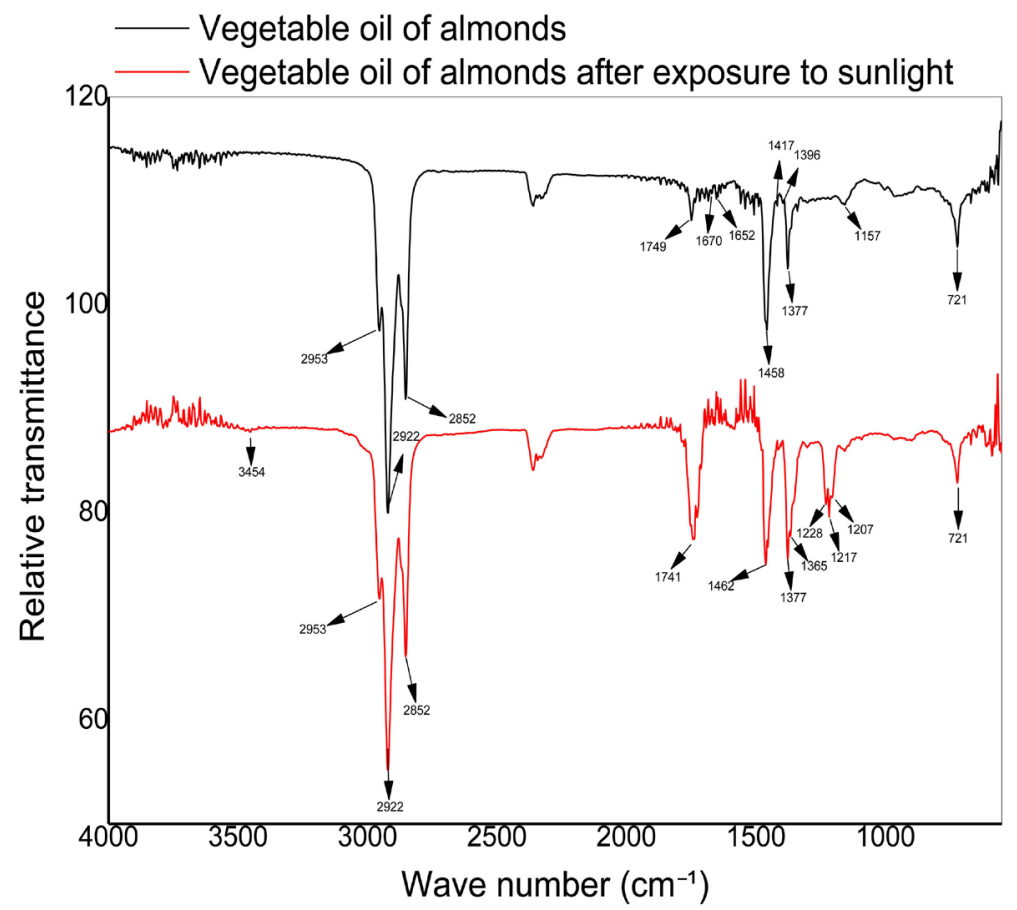

Figure 3. FTIR spectrum of Almond oil, before (up) and after exposure to light (down).

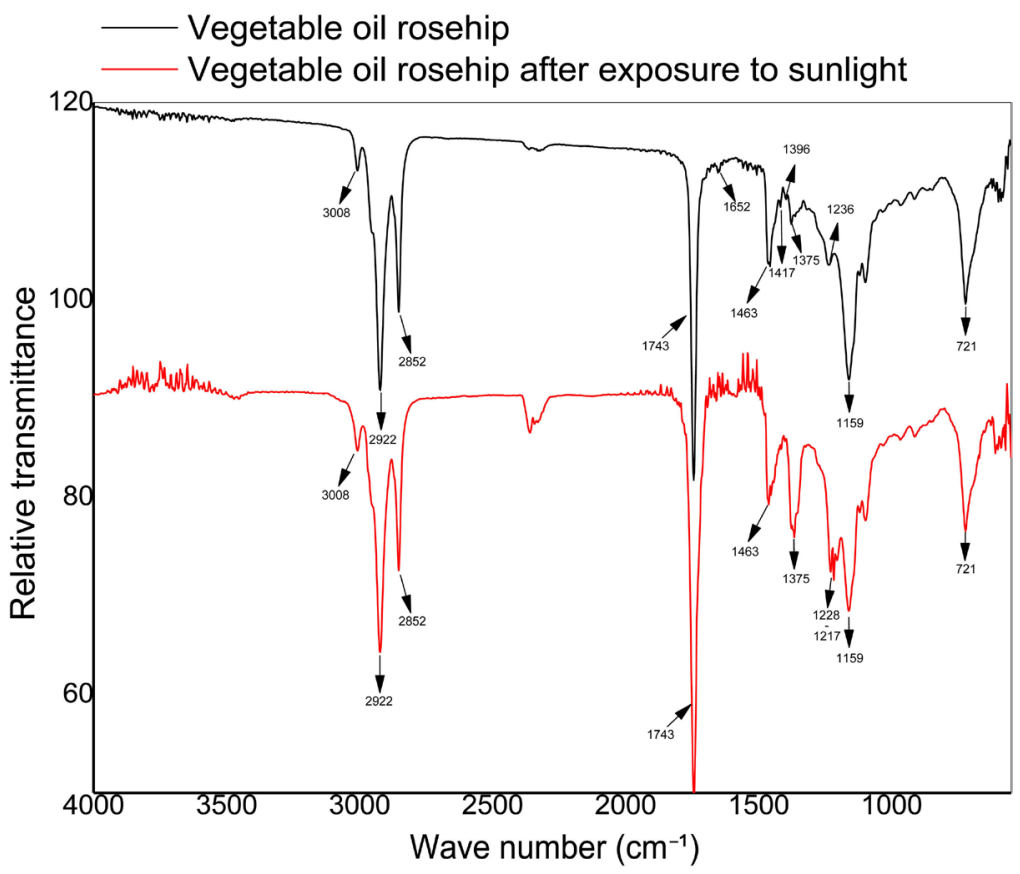

Figure 4. FTIR spectrum of Rosehip oil, before (up) and after exposure to light (down).

The FTIR spectra analyzed show that the functional groups responsible for the typical absorption bands of the triacylglycerides, in the middle infrared region, are attributed to the carbonyl stretch $(\mathrm{C}=\mathrm{O})$ at $1747 \mathrm{~cm}^{-1}$ and signal of average intensity close to $1161 \mathrm{~cm}^{-1}$ characteristic of the axial deformation of the group (C-O) of the ester group. Intense bands with absorbances at 2924 and $2853 \mathrm{~cm}^{-1}$ are assigned, respectively, the symmetric and asymmetric axial strain vibrations 
of the $\left(\mathrm{CH}_{2}\right)$ groups of fatty acids in triacylglycerides according to Guill'en, et al. [23].

It is possible to observe from the results obtained from the plotted FTIR spectra,

Table 2. Values of the characteristic absorption bands for each group present in Andiroba oil, the respective areas, the modes of vibration before and after exposure to sunlight.

\begin{tabular}{|c|c|c|c|c|c|}
\hline \multicolumn{2}{|c|}{ Sample "in natura" } & \multicolumn{2}{|c|}{ Sample after sun exposure } & \multirow{2}{*}{$\begin{array}{c}\text { Organic group } \\
-\end{array}$} & \multirow[t]{2}{*}{ Vibration mode } \\
\hline $\begin{array}{l}\text { Wave number } \\
\qquad \mathrm{cm}^{-1}\end{array}$ & $\begin{array}{l}\text { Band area } \\
\mathrm{cm}^{2}\end{array}$ & $\begin{array}{l}\text { Wave number } \\
\qquad \mathrm{cm}^{-1}\end{array}$ & $\begin{array}{l}\text { Band area } \\
\mathrm{cm}^{2}\end{array}$ & & \\
\hline 3005 & 3.71 & 3111 a 3005 & 58.67 & $=\mathrm{C}-\mathrm{H}(\mathrm{cis})$ & Axial deformation \\
\hline $2953,2922,2852$ & 2232.25 & $2953,2922,2852$ & 2081 & $\begin{array}{l}-\mathrm{C}-\mathrm{H}\left(\mathrm{CH}_{3}\right) \\
-\mathrm{C}-\mathrm{H}\left(\mathrm{CH}_{2}\right)\end{array}$ & $\begin{array}{c}\text { Asymmetric and symmetrical axial } \\
\text { deformation }\end{array}$ \\
\hline 1747 & 118.47 & 1739 & 1788.65 & $-\mathrm{C}=\mathrm{O}$ & Axial deformation \\
\hline 1670 & 2.65 & Absent & - & $\mathrm{C}=\mathrm{C}$ (trans) & Axial deformation \\
\hline 1652 & 9.42 & Absent & - & $\mathrm{C}=\mathrm{C}(\mathrm{cis})$ & Axial deformation \\
\hline 1462 & 306.87 & 1462 & 500.87 & $-\mathrm{C}-\mathrm{H}\left(\mathrm{CH}_{2}\right)$ & Symmetrical angular deformation \\
\hline 1417 & 2.39 & Absent & - & $=\mathrm{C}-\mathrm{H}(\mathrm{cis})$ & Angular deformation \\
\hline 1396 & 2.44 & Absent & - & $=\mathrm{C}-\mathrm{H}(\mathrm{cis})$ & Angular deformation \\
\hline 1377 & 101.15 & 1375 & 817.33 & $-\mathrm{C}-\mathrm{H}\left(\mathrm{CH}_{3}\right)$ & Symmetrical angular deformation \\
\hline 1215 & 4.63 & $1228,1217,1205$ & 777.03 & $\mathrm{C}-\mathrm{O}$ & Axial deformation \\
\hline 1161 & 99.86 & 1161 & 36.43 & $\mathrm{C}-\mathrm{O}$ & Axial deformation \\
\hline 721 & 123.21 & 721 & 90.22 & $-\left(\mathrm{CH}_{2}\right) \mathrm{n}-$ & Asymmetric angular deformation \\
\hline
\end{tabular}

Table 3. Values of the characteristic absorption bands for each group present in Copaiba oil, the respective areas, the modes of vibration before and after exposure to sunlight.

\begin{tabular}{cccccc}
\hline \multicolumn{2}{c}{ Sample "in natura" } & \multicolumn{2}{c}{ Sample after sun exposure } \\
\hline $\begin{array}{c}\text { Wave number } \\
\mathbf{c m}^{-1}\end{array}$ & $\begin{array}{c}\text { Band area } \\
\mathbf{c m}^{2}\end{array}$ & $\begin{array}{c}\text { Wave number } \\
\mathbf{c m}^{-1}\end{array}$ & $\begin{array}{c}\text { Band area } \\
\mathrm{cm}^{2}\end{array}$ & - & Vibration mode \\
\hline $2951,2920,2852$ & 2426.27 & $2951,2920,2852$ & 2319.07 & $\begin{array}{c}-\mathrm{C}-\mathrm{H}\left(\mathrm{CH}_{3}\right), \\
-\mathrm{C}-\mathrm{H}\left(\mathrm{CH}_{2}\right)\end{array}$ & $\begin{array}{c}\text { Asymmetric and symmetrical } \\
\text { axial deformation }\end{array}$ \\
1747 & 85.42 & 1747 & 83.11 & $-\mathrm{C}=\mathrm{O}$ & Axial deformation \\
1670 & 3.11 & Absent & - & $\mathrm{C}=\mathrm{C}($ trans $)$ & Axial deformation \\
1652 & 10.35 & Absent & - & $\mathrm{C}=\mathrm{C}(\mathrm{cis})$ & Axial deformation \\
1456 & 340.99 & 1460 & 388.63 & $-\mathrm{C}-\mathrm{H}(\mathrm{CH})$ & Symmetrical angular deformation \\
1417 & 2.48 & Absent & - & $=\mathrm{C}-\mathrm{H}(\mathrm{cis})$ & Angular deformation \\
1396 & 1.89 & Absent & - & $=\mathrm{C}-\mathrm{H}(\mathrm{cis})$ & Angular deformation \\
1375 & 110.29 & 1375 & 134.35 & $-\mathrm{C}-\mathrm{H}\left(\mathrm{CH}_{3}\right)$ & Symmetrical angular deformation \\
1230 & 6.55 & 1238 & 5.36 & $\mathrm{C}-\mathrm{O}$ & Axial deformation \\
1217 & 0.85 & Absent & - & $\mathrm{C}-\mathrm{O}$ & Axial deformation \\
1163 & 79.60 & 1159 & 72.47 & $\mathrm{C}-\mathrm{O}$ & Axial deformation \\
721 & 72.45 & 721 & 68.78 & $-(\mathrm{CH}) \mathrm{n}-$ & Asymmetric angular deformation \\
\hline
\end{tabular}


Table 4. Values of the characteristic absorption bands for each group present in Almond oil, the respective areas, and the modes of vibration before and after exposure to sunlight.

\begin{tabular}{cccccc}
\hline \multicolumn{2}{c}{ Sample "in natura" } & \multicolumn{2}{c}{ Sample after sun exposure } & Organic group & Vibration mode \\
\hline $\begin{array}{c}\text { Wave number } \\
\mathbf{c m}^{-1}\end{array}$ & $\begin{array}{c}\text { Band area } \\
\mathbf{c m}^{2}\end{array}$ & $\begin{array}{c}\text { Wave number } \\
\mathbf{c m}^{-1}\end{array}$ & $\begin{array}{c}\text { Band area } \\
\mathbf{c m}^{2}\end{array}$ & - & - \\
\hline $2953,2922,2852$ & 2335.38 & $2953,2922,2852$ & 2197.72 & $\begin{array}{c}-\mathrm{C}-\mathrm{H}\left(\mathrm{CH}_{3}\right), \\
-\mathrm{C}-\mathrm{H}\left(\mathrm{CH}_{2}\right)\end{array}$ & $\begin{array}{c}\text { Asymmetric and symmetrical axial } \\
\text { deformation }\end{array}$ \\
1749 & 30.92 & 1741 & 482.69 & $-\mathrm{C}=\mathrm{O}$ & Axial deformation \\
1670 & 2.94 & Absent & - & $\mathrm{C}=\mathrm{C}($ trans $)$ & Axial deformation \\
1652 & 11.00 & Absent & - & $\mathrm{C}=\mathrm{C}(\mathrm{cis})$ & Axial deformation \\
1458 & 323.86 & 1462 & 409.14 & $-\mathrm{C}-\mathrm{H}(\mathrm{CH})$ & Symmetrical angular deformation \\
1417 & 2.72 & Absent & - & $=\mathrm{C}-\mathrm{H}(\mathrm{cis})$ & Angular deformation \\
1396 & 3.10 & Absent & - & $=\mathrm{C}-\mathrm{H}(\mathrm{cis})$ & Angular deformation \\
1377 & 102.60 & 1377 & 351.89 & $-\mathrm{C}-\mathrm{H}\left(\mathrm{CH}_{3}\right)$ & Symmetrical angular deformation \\
Ausente & - & $1228,1217,1207$ & 218.29 & $\mathrm{C}-\mathrm{O}$ & Axial deformation \\
1157 & 50.52 & 1157 & 19.91 & $\mathrm{C}-\mathrm{O}$ & Axial deformation \\
721 & 74.17 & 721 & 68.12 & $-\left(\mathrm{CH} \mathrm{H}_{2}\right) \mathrm{n}-$ & Asymmetric angular deformation \\
\hline
\end{tabular}

Table 5. Values of the characteristic absorption bands for each group present in Rosehip oil, the respective areas, and the modes of vibration before and after exposure to sunlight.

\begin{tabular}{cccccc}
\hline \multicolumn{2}{c}{ Sample "in natura" } & \multicolumn{2}{c}{ Sample after sun exposure } & Organic group & Vibration mode \\
\hline $\begin{array}{c}\text { Wave number } \\
\mathbf{c m}^{-1}\end{array}$ & $\begin{array}{c}\text { Band area } \\
\mathbf{c m}^{2}\end{array}$ & $\begin{array}{c}\text { Wave number } \\
\mathbf{c m}^{-1}\end{array}$ & $\begin{array}{c}\text { Band area } \\
\mathbf{c m}^{2}\end{array}$ & - & - \\
\hline 3008 & 51.01 & 3008 & 72.09 & $=\mathrm{C}-\mathrm{H}(\mathrm{cis})$ & Axial deformation \\
2922,2852 & 1599.81 & 2922,2852 & 1518.66 & $-\mathrm{C}-\mathrm{H}\left(\mathrm{CH}_{2}\right)$ & Asymmetric and symmetrical axial \\
1743 & 721.82 & 1743 & 1344.08 & $-\mathrm{C}=\mathrm{O}$ & deformation \\
1670 & 1.58 & Absent & - & $\mathrm{C}=\mathrm{C}(\mathrm{trans})$ & Axial deformation \\
1652 & 7.90 & Absent & - & $\mathrm{C}=\mathrm{C}(\mathrm{cis})$ & Axial deformation \\
1463 & 233.74 & 1462 & 311.73 & $-\mathrm{C}-\mathrm{H}(\mathrm{CH})$ & Axial deformation \\
1417 & 7.27 & Absent & - & $=\mathrm{C}-\mathrm{H}(\mathrm{cis})$ & Angular deformation \\
1396 & 6.62 & Absent & - & $=\mathrm{C}-\mathrm{H}(\mathrm{cis})$ & Angular deformation \\
1375 & 79.28 & 1375 & 339.59 & $-\mathrm{C}-\mathrm{H}(\mathrm{CH})$ & Symmetrical angular deformation \\
1236 & 76.62 & $1228,1217,1205$ & 221.04 & $\mathrm{C}-\mathrm{O}$ & Axial deformation \\
1159 & 479.20 & 1159 & 316.89 & $\mathrm{C}-\mathrm{O}$ & Axial deformation \\
721 & 692.22 & 721 & 693.97 & $-(\mathrm{CH}) \mathrm{n}-$ & Asymmetric angular deformation \\
\hline
\end{tabular}

and tabulated values to identify four main trends that facilitate the analysis of the degradative effect related to exposure to sunlight on the studied samples.

The first trend, and perhaps the most relevant to assess the oxidative effect on the samples, is the disappearance of the characteristic bands of unsaturation in 
the spectra of the oil samples after exposure to sunlight. In all samples studied under exposure condition, thus the disappearance of the bands in 1670, 1652, 1417 and $1396 \mathrm{~cm}^{-1}$. As described by Silverstein et al. [25], these bands correspond respectively to the axial strain between trans carbons, axial strain between cis carbons, angular strain (=C-H cis), and also angular strain (=C-H cis). This trend expresses a phenomenon that was already expected, the attack on unsaturation, which are points of the chain of great reactivity, where there is a great electronic density conducive to the attack of an oxidizing agent, which makes the oil more sensitive to degradation.

The second trend that can be observed is the increase in the characteristic band of axial deformation of the carbonyl group between 1739 and $1749 \mathrm{~cm}^{-1}$. The only exception is copaiba oil. This factor indicates the occurrence of sample oxidation, since according to Rampazzo (5), hydroperoxides are the main products of the oxidation of vegetable oils, and these in turn are compounds of high instability that tend to decompose into secondary compounds such as aldehydes and ketones. This explains the increase in the area of the characteristic band of carbonyl group $(\mathrm{C}=\mathrm{O})$.

A third observed trend was the increase in the methylene $(\mathrm{C}-\mathrm{H})$ stretch band between 1463 and $1456 \mathrm{~cm}^{-1}$, which again would be caused by the oxidative process, relating not only to the decrease in the amount of unsaturation in the sample but also to the fractionation of the carbon chain into smaller molecules by the oxidative process.

The fourth tendency to be observed is the increase in the area of the characteristic stretch band (C-H) of terminal methyl groups between 1377 and 1375 $\mathrm{cm}^{-1}$. This phenomenon suggests that the carbon chain of the samples was fractionated into smaller molecules by the oxidative process. Where during lipid oxidation reactions, fatty acids esterified into triglycerols and phospholipids decompose, forming small and volatile molecules that produce the unwanted aromas known as oxidative rancidity, according to Fennema et al. [26].

According to Smith et al. [27], a band in $1739 \mathrm{~cm}^{-1}$ may appear due to oxidation, which indicates the decomposition of hydroperoxides in carbonyl compounds, that is, in secondary oxidation products.

According to Vlachos et al., [28], the band at $1742 \mathrm{~cm}^{-1}$ is related to the stretching of the ester carbonyl group, which demonstrated in their studies, a band widening in this region when the sample is submitted to high temperatures. This information is due to the formation of aldehyde compounds or other secondary products of oxidation that cause an absorption in $1746 \mathrm{~cm}^{-1}$, related to the vibration of triglyceride carbonyl ester stretching.

According to Rohman et al. [29], absorption bands at $1117 \mathrm{~cm}^{-1}$ arise from vibrations from the ether bond stretches in triacylglycerols, whereas the stretching vibrations of the bond (C-O) of the ester groups occur next $1163 \mathrm{~cm}^{-1}$, as described by Shi et al. [30].

In addition to the trends mentioned, the samples were also observed, after 
exposure to sunlight, only in the oil samples: almonds, andiroba and rosehip, that is, Figure 1, Figure 3 and Figure 4, the appearance of a low intensity band between 3452 and $3454 \mathrm{~cm}^{-1}$, which is a characteristic band of hydroperoxides, one of the main products of oil oxidation, mentioned above.

Another important point to note is the decrease in the characteristic band of axial strain (=C-H) between 3008 and $3005 \mathrm{~cm}^{-1}$, which was expected for samples of andiroba and rosehip oils did not occur (Figure 1 and Figure 4). Still occurring the opposite to the expected, an increase in the area of this band. However, what observe was the increase in area that would not be related to variation in the axial strain band $=\mathrm{CH}$, but to the appearance of an $\mathrm{OH}$ stretch band, characteristic of hydroxyl, in the region close to $3000 \mathrm{~cm}^{-1}$ and overlapping the stretch band $(=\mathrm{CH})$. Note the widening of the band between 3008 and $3005 \mathrm{~cm}^{-1}$ for higher frequencies. The appearance of the characteristic hydroxyl band in turn can be analyzed as a result of the oxidation of the samples since alcohols are one of the lipid oxidation products.

In relation to the carbonyl group $(-\mathrm{C}=\mathrm{O})$, it can be observed that there was an increase of practically fifteen times in the area value in $\mathrm{cm}^{2}$ for samples of Andiroba oil and almonds, suggesting the formation of aldehyde compounds and other products secondary. While Copaiba oils were practically unchanged and Rosa Mosqueta increased by almost two times in relation to samples after the exposure process.

As described by Nascimento Filho et al. [31], the absorption band to the methylene group $\left(=\mathrm{CH}_{2}\right)$, related to angular deformation of medium intensity next to $1460 \mathrm{~cm}^{-1}$, tends to stay due to the oxidation process, reported in your study by heating. What can also be observed, in this work for all samples studied, its permanence and even an increase in area in $\mathrm{cm}^{2}$, after 90 days of exposure to solar radiation.

The absorption band at $1417 \mathrm{~cm}^{-1}\left(-\mathrm{CH}_{3}\right)$, that is, angular deformation in the plane, there is an absence in all samples evaluated after the exposure process, the same observed by Nascimento Filho et al. [31]. Where this change is possibly related to the progressive increase in the degree of polymerization due to the appearance of cross-links and consequent decrease in double bonds, as can be seen in all samples studied.

It can also be observed that the absorption band to the group (C-O) 1161 $\mathrm{cm}^{-1}$, relative to angular deformation in the plane, stay after the exposure process with a decrease in the values in area $\left(\mathrm{cm}^{2}\right)$, being higher $(63.5 \%)$ for Andiroba, (60.5\%) for Almonds, (33.8\%) for Rosehip and (9.0\%) for Copaíba. Suggesting a possible formation of aldehyde compounds and other secondary compounds, as can be seen by the increase in the band $(-\mathrm{C}=\mathrm{O})$, after the sun exposure process.

Finally, it can also be observed that the absorption band $721 \mathrm{~cm}^{-1}(-\mathrm{CH})$, referring to symmetrical angular deformation in the plane and asymmetric angular deformation outside the plane, remains with values close to the area $\left(\mathrm{cm}^{2}\right)$, even 
after the process of exposure to sunlight for all evaluated oils, the same process was observed by Nascimento Filho et al. [31], following the polymerization process of Andiroba oil under heating at $180^{\circ} \mathrm{C}$, for 8 hours, but the absence of the band after 16 hours of heating. For the present study, the permanence of the $721 \mathrm{~cm}^{-1}$ band can be explained by the daily temperature and the exposure time, maximum daily temperature of $35^{\circ} \mathrm{C}$ and for 90 days, respectively. Therefore, at a temperature of $35^{\circ}$ and exposure time of 90 days, they were not enough to promote significant changes in this band of $721 \mathrm{~cm}^{-1}$, which may show the low polymerization of the samples.

\section{Conclusions}

FTIR evaluation has proved to be an effective technique for studying the degradation process in vegetable oils, and used in conjunction with ORIGINPro 9.1 software and in the evaluation of the calculation of the area of altered bands with characteristic bands for a given region.

After exposure to sunlight, the disappearance of the characteristic bands of unsaturation in the FTIR spectrum was observed, indicating the high degradation and/or oxidation of the samples evaluated as a function of solar radiation.

Clearly, the observed results demonstrate the sensitivity to light that oils rich in polyunsaturated fatty acids present. Therefore, to ensure good durability of these oils, we recommended adequate storage and protected them from sunlight with possible use of a amber bottle, thus preventing their oxidation which is related to the appearance of undesirable components and ensuring the conservation of polyunsaturated fatty acids.

\section{Conflicts of Interest}

The authors declare no conflicts of interest regarding the publication of this paper.

\section{References}

[1] Farias, E.A., Leles, M.I.G., Ionashiro, M., Suppa, T.O. and Antoniosi Filho, N.R. (2002) Study of the Thermal Stability of Oil and Vegetable Fats by TG/DTG and DTA. Eclectic Chemistry, 27, 111-119. https://doi.org/10.1590/S0100-46702002000100010

[2] Pereira, W.A. (2012) Multivariate Calibration of Vegetable Oil Mixtures Using Medium Infrared Spectroscopy. Master Dissertation, Agricultural Sciences Course, $\mathrm{Pa}-$ raíba State University, João Pessoa.

[3] Silva, A.R. (2004) Aromatherapy in Dermatology and Aesthetics. Roca, São Paulo.

[4] Allinger, N.L., Cava, M.P., Johnson, C.R., Lebel, N.A. and Stevens, C.L. (2009) Organic Chemistry. 2nd Edition, LTC, Rio de Janeiro.

[5] Rampazzo, V. (2015) Evaluation of Termal Degadation of Vegetable Oils by Thermogravimetry, Gas Chromatography and Médium Infrared Spectroscopy. Master Dissertation, Food Engineering Course, Federal University of Paraná, Curitiba.

[6] Silva, L.R. (2018) Physico-Chemical Properties and Fatty Acid Profile of Andiroba 
Oil. Native Agricultural and Environmental Research, 6, 147-152.

[7] Silva, A.E.S. (2012) Identification and Quantification with Chromatographic Techniques of Fatty Acids with Pharmacological Potential in Amazonian Fruits. Master Dissertation, Nuclear Technology Course, IPEN, São Paulo.

[8] Askin, M.A., Balta, M.F., Tekintas, F.E., Kazankaya, A. and Balta, F. (2007) Fatty Acid Composition Affected by Kernel Weightin Almond [Prunus dulcis (Mill.) D.A. Webb.] Genetic Resources. Journal of Food Composition and Analysis, 20, 7-12. https://doi.org/10.1016/j.jfca.2006.06.005

[9] Santos, J.S., Duarte Vieira, A.B. and Kamada, I. (2009) The Rosehip in the Treatment of Open Wounds: A Review. Revista Brasileira de Enfermagem, 62, 457-462. https://doi.org/10.1590/S0034-71672009000300020

[10] Ferrari, M., Oliveira, M.S.C., Nakano, A.K. and Rocha-Filho, P.A. (2007) Determination of the Sun Protection Factor (SPF) in Vitro and in Vivo of Emulsions with Andiroba Oil (Carapa guianensis). Brazilian Journal of Pharmacognosy, São Paulo, 17, 626-630. https://doi.org/10.1590/S0102-695X2007000400023

[11] Ferreira, L.S. (2018) Irrigation Déficit in Almod (Prunus dulcis L.): Different Physiological Strategies to Assess the Cultures's Hydric State. Doctorate Thesis, Plant Production Course, State University of Northern Fluminense Darcy Ribeiro, Rio de Janeiro.

[12] Souza, E.C. (2007) Study of the Oxidation of Soybean Oil with Different Concentrations of Anti-Oxidant Additives, for Use in Heat Quenching Treatments. Master Dissertation, Materials Engineering Course, University of São Paulo, São Paulo.

[13] Schneider, R.C.S. (2002) Extraction, Characterization and Transformation of Castle Oil. Doctorate Thesis, Chemistry Course, Federal University of Rio Grande do Sul, Porto Alegre.

[14] Nenadis, N., Tsikouras, I., Xenikakis, P. and Tsimidou, M.Z. (2013) Fourier Transform MID-Infrared Spectroscopy Evaluation of Early Stages of Virgin Olive Oil Autoxidation. European Journal of Lipid Science and Technology, 115, 526-534. https://doi.org/10.1002/ejlt.201200317

[15] Ismail, A.A., Van de Voort, F.R. and Sedman, J. (1997) Fourier Transform Infrared Spectroscopy: Principles and Applications. Techniques and Instrumentation in Analytical Chemistry, 18, 93-139. https://doi.org/10.1016/S0167-9244(97)80013-3

[16] Uncu, O. and Ozen, B. (2015) Prediction of Various Chemical Parameters of Olive Oils with Fourier Transform Infrared Spectroscopy. Food Science and Technology, 63, 978-984. https://doi.org/10.1016/j.lwt.2015.05.002

[17] Marina, A.M., Wan Rosli, W.I. and Noorhidayah, M. (2013) Quantitative Analysis of Peroxide Value in Virgin Coconut Oil by ATR-FTIR Spectroscopy. The Open Conference Proceedings Journal, 4, 53-56. https://doi.org/10.2174/2210289201304020053

[18] Jiang, X.M., Li, S., Xiang, G.Q., Li, Q.H., Fan, L., He, L.J. and Gu, K.R. (2016) Determination of the Acid Value of Edible Oils via FTIR Spectroscopy Based on the O-H Stretching Band. Food Chemistry, 212, 585-589. https://doi.org/10.1016/j.foodchem.2016.06.035

[19] Simões, C.M., Schenkel, E.P., Gosmann, G., Mello, J.C.P., Mentz, L.A. and Petrovick, P.R. (2004) From the Plant to the Medicine. 5th Edition, UFSC/UFRGS Publisher, Pharmacognosy, Florianópolis/Porto Alegre.

[20] Solomons, T.W.G. (2001) Organic Chemistry. 7th edition, Editora LTC, Rio de Janeiro.

[21] Ramalho, V.C. and Jorge, N. (2006) Antioxidants Used in Oils, Fats and Fatty Foods. 
Química Nova, 29, 755-760. https://doi.org/10.1590/S0100-40422006000400023

[22] Souza, A.M. and Poppi, R.J. (2012) Didactic Chemistry Experiment for Exploratory Analysis of Vegetable Oils Co-Edible by Middle Infrared Spectroscopy and Principal Component Analysis: A Tutorial, Part I. Química Nova, 35, 223-229. https://doi.org/10.1590/S0100-40422012000100039

[23] Guill'en, M.D. and Cabo, N. (2002) Fourier Transform Infrared Spectra Data versus Peroxide and Anisidine Values to Determine Oxidative Stability of Edible Oils. Food Chemistry, 77, 503-510. https://doi.org/10.1016/S0308-8146(01)00371-5

[24] Srivastava, Y. and Semwal, A.D. (2015) A Study on Monitoring of Frying Performance and Oxidative Stability of Virgin Coconut Oil (VCO) during Continuous/Prolonged Deep Fat Frying Process Using Chemical and FTIR Spectroscopy. Journal of Food Science and Technology, 52, 984-991.

https://doi.org/10.1007/s13197-013-1078-8

[25] Silverstein, R.M., Webster, F.X. and Kiemle, D.J. (2006) Spectrometric Identification of Organic Compounds. 7th Edition, LTC, Rio de Janeiro.

[26] Fennema, O.R. Damodaran, S. and Parkin, K.L. (2010) Food Chemistry. 4th Edition, Editora Artmed, Porto Alegre.

[27] Smith, S.A., King, R.E. and Min, D.B. (2007) Oxidative and Thermal Stabilities of Genetically Modified High Oleic Sunflower Oil. Food Chemistry, 102, 1208-1213. https://doi.org/10.1016/j.foodchem.2006.06.058

[28] Vlachos, N., Skopelitis, Y., Psaroudaki, M., Konstantinidou, V., Chatzilazarou, A. and Tegou, E. (2006) Applications of Fourier Transform Infrared Spectroscopy to Edible Oils. Analytica Chimica Acta, 573, 459-465. https://doi.org/10.1016/j.aca.2006.05.034

[29] Rohman, A., Kuwat, T., Retno, S., Yuny, E. and Tridjoko, W. (2012) Fourier Transform Infrared Spectroscopy Applied for Rapid Analysis of Lard in Palm Oil. International Food Research Journal, 19, 1161-1165.

https://search.proquest.com/openview/0636b430724b060792c35ebea7b6abcd/1?pqorigsite $=$ gscholar $\& \mathrm{cbl}=816390$

[30] Shi, L., Liu, Z., Li, J. and Qin, Z. (2017) Analysis of Edible Vegetable Oils by Infrared Absorption Spectrometry. Advances in Engineering Research, 86, 286-289. https://doi.org/10.2991/eame-17.2017.67

[31] Nascimento Filho, W.B., Silva, H.E.B., Sousa, R.C.P. and Souza, O.S. (2019) FTIR Infrared Spectroscopy and X-Ray Diffractometry Applied to Monitor the Polymerization Process of Andiroba Oil. Revista Virtural Química, 11, 922-936.

https://doi.org/10.21577/1984-6835.20190064 